American J. of Engineering and Applied Sciences 2 (4): 759-763, 2009

ISSN 1941-7020

(C) 2009 Science Publications

\title{
Relaxation of Residual Stress Part 2: Relaxation of Stage 2
}

\author{
${ }^{1}$ Omar Suliman Zaroog, ${ }^{1,2}$ Aidy Ali, ${ }^{1,2}$ B.B. Sahari and ${ }^{3}$ Rizal Zahari \\ ${ }^{1}$ Department of Mechanical and Manufacturing Engineering, Faculty of Engineering, \\ University Putra Malaysia, UPM, 43400 Serdang, Selangor, Malaysia \\ ${ }^{2}$ Institute of Advanced Technology, University Putra Malaysia, 43400 UPM, \\ Serdang Selangor, Malaysia \\ ${ }^{3}$ Department of Aerospace Engineering, Faculty of Engineering, \\ University of Putra Malaysia, 43400 UPM Serdang, Selangor, Malaysia
}

\begin{abstract}
Problem statement: Compressive residual stress induced by surface treatment such as shot peening increased component's fatigue life. However the initial induced residual stresses relax during component operating life and it is important to consider the relaxation in the design. Approach: In this study, a 2024-T351 aluminum alloy specimens were shot peened into three shot peening intensities condition to induce compressive residual stresses. Then fatigue test for two loads was performed for the 10, 1000 and 10000 cyclic loads. The initial residual stresses at the initial condition and after 10, 1000 and 10000 cycle of fatigue loading were measured using X-ray diffraction method. Results: The results showed that the relaxation of the residual stress for the load $15.5 \mathrm{kN}$ is less than the relaxation of the load $30 \mathrm{kN}$ for the three shot peening intensity. The maximum relaxation for load $15.5 \mathrm{kN}$ is $46 \%$ of the initial residual stress at 10000 cycles for intensity 0.009 A while the maximum relaxation for load $30 \mathrm{kN}$ is $54 \%$ at 10000 cycles for the intensity of $0.0054 \%$ A. this result indicated that the residual stress relaxation depended on the load amplitude. Conclusion: The initial residual stress did not remain stable during the component's fatigue life. Within the second phase relaxation, microplastic strains accumulating from cycle to cycle. The residual stress relaxation for second phase is in logarithmic relationship.
\end{abstract}

Key words: Residual stress, residual stress relaxation, shot peening, X-ray diffraction

\section{INTRODUCTION}

To improve fatigue resistance, one of the known ways is by using the shot peening process that induces beneficial compressive residual stress in the outer surface layers of the material, to retard the initiating and propagating of fatigue $\mathrm{cracks}^{[1,2]}$. Peening intensity or known as impact energy is dependent on the velocity, hardness, size and weight of the shot and on the angle at which the shot impinges against the surface of the work-piece. Intensity is expressed in terms of the arc height of an Almen test strip. Almen strips are made of SAE 1070 spring steel strips. They come in three thicknesses, for different sensitivity, termed A, C and $\mathrm{N}$ strips. They are the primary standard of quality control.

However, the Compressive Residual Stress Field (CRSF) induced by shot peening has been observed to be relax of over the fatigue life ${ }^{[3-5]}$. Even with partial relaxation of the compressive residual stress, Mattson and Coleman ${ }^{[6]}$ found a beneficial effect on fatigue life. They concluded that fatigue lives were below the predictions if residual stress relaxation was not taken into consideration. The understanding and accurately quantifying residual stress relaxation and redistribution under cyclic mechanical load still remain as a technical challenge for the researchers ${ }^{[7]}$.

During the fatigue cycles, the residual stress relaxation can be divided into two stages: The first cycle relaxation due to the surface yielding and the following cycles which have gradual relaxation. In these two stages, the residual stress of shot peened specimens decrease considerably when compared to those with no fatigue cycles.

Cyclic relaxation is affected mainly by initial magnitude and gradient of the residual stress field and degree of cold working, fatigue stress amplitude, mean stress ratio, number of cycles, material cyclic stressstrain response and degree of cyclic work hardening/softening ${ }^{[8]}$.

Corresponding Author: Omar Suliman Zaroog, Department of Mechanical and Manufacturing Engineering,

Faculty of Engineering, University Putra Malaysia, UPM, 43400 Serdang, Selangor, Malaysia 
In practice, however, the difficulties in measuring residual stress relaxation during component operation normally impede the consideration of tracking this relaxation and assessing its effect on the remained fatigue life, it has been found that the rate of residual stress relaxation can be drastic in the early stages of fatigue cycling ${ }^{[9]}$.

Kodama $^{[10]}$ measured residual stress relaxation on the surface of shot-peened specimens, using X-ray diffraction techniques. He proposed linear logarithmic decrease relationship between residual stress and load cycles only after the first cycle.

The relaxation of residual stress in the first and second cycles for 2024-T351 was investigated, the result showed that the compressive residual stress in the first load cycle can be relaxed by more than $45 \%{ }^{[11]}$. It is worth noting that Kodama's linear logarithmic relationship was not applicable to drastic initial residual stress reductions in the first few cycles.

In this study, the relaxation of residual stress due to cyclic loading is investigated. The focused was only given on the relaxation of the residual stress after the first cycle. The residual stress relaxation of the first cycle was studied in our previous study ${ }^{[11]}$.

\section{MATERIALS AND METHODS}

Experiment: The study was undertaken on aluminum alloy AA2024-T351 as a plate with a thickness of 6 $\mathrm{mm}$, tensile strength of $484 \mathrm{MPa}$, yield strength of 348 $\mathrm{MPa}$ and an elongation of $15 \%$. The chemical compositions of the tested material are given in Table 1. The fatigue specimens were scaled in accordance with airbus standard ${ }^{[12]}$ as shown in Fig. 1. The specimens were treated with three intensities of shot peening: $0.0054,0.0067$ and $0.0090 \mathrm{~A}$ the other parameters of shot peening were kept confidential to the shot peening provider.

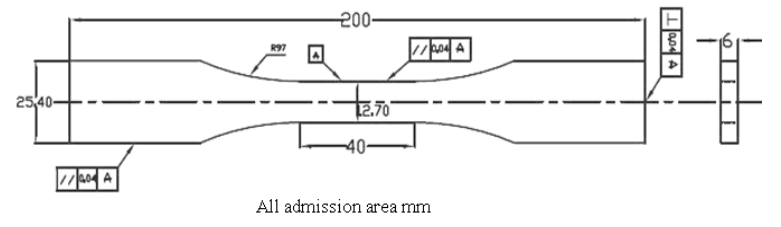

Fig. 1: Fatigue specimen

Table 1: Specific chemical composition of 2024-T351 Al Alloy (wt \%)

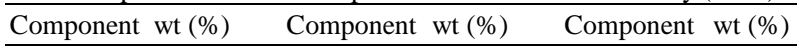

\begin{tabular}{llllll}
\hline $\mathrm{Al}$ & 93.50 & $\mathrm{Fe}$ & 0.50 & $\mathrm{Si}$ & 0.50
\end{tabular}

$\begin{array}{llllll}\mathrm{Cr} & 0.10 & \mathrm{Mg} & 1.20-1.80 & \mathrm{Ti} & 0.15\end{array}$

$\begin{array}{lllll}\mathrm{Cu} & 3.80-4.90 \mathrm{Mn} & 0.30-0.90 & \mathrm{Zn} & 0.25\end{array}$

\begin{tabular}{llllll}
$\mathrm{Ni}$ & 0.05 & $\mathrm{~Pb}$ & 0.05 & $\mathrm{Zr}$ & 0.20 \\
\hline
\end{tabular}

Two loads levels of 15.5 and $30 \mathrm{KN}$ were chosen for fatigue test. Cyclic load of 10, 1000 and 10000 cycles were applied to the specimens for loads 15.5 and $30 \mathrm{KN}$, for the three shot peening intensities. The specimens were tested in material testing machine Instron 810 fatigue tests with load ratio $(\mathrm{R})$ of 0.1 at frequency of $30 \mathrm{~Hz}$ and in the room temperature.

Residual stress measurement: Residual stresses were measured using X-ray diffraction. Residual stress measurements were made at the surface only in the longitudinal direction at the center of the gage length on the width side. X-ray diffraction residual stress measurements were performed using a two-angle sinesquared-psi technique, in accordance with SAE HS784, employing the diffraction of chromium K-alpha radiation from the (311) planes of the FCC structure of the 2024-T351 aluminum alloy. The diffraction peak angular positions at each of the psi tilts employed for measurement were determined from the position of the K-alpha 1 diffraction peak separated from the superimposed K-alpha doublet assuming a Pearson VII function diffraction peak profile in the high back-reflection region.

The samples were rocked through an angular range of $\pm 1.5^{\circ}$. Around the mean psi angles during measurement to integrate the diffracted intensity over more grains in order to minimize the influence of the grain size. below:

Details of the diffract meter fixturing are outlined

Incident beam divergence: $\quad 1.0^{\circ}$

Detector: $\quad$ Scintillation set for $90 \%$ acceptance of the chromium K-alpha energy

Psi rotation: $\quad 10.00$ and $50.00^{\circ}$

Irradiated area: $\quad 0.20 \times 0.20 \mathrm{in} .(5.1 \times 5.1 \mathrm{~mm})$

The value of the $\mathrm{x}$-ray elastic constant, $\mathrm{E} /(1+\mathrm{v})$, required to calculate the macroscopic residual stress from the strain measured normal to the (311) planes of 2024-T351 aluminum alloy was previously determined empirically by employing a simple rectangular beam manufactured from 2024-T351 aluminum alloy loaded in four-point bending on the diffractometer to known stress levels and measuring the resulting change in the spacing of the (311) planes in accordance with ASTM E1426.

\section{RESULTS}

The fatigue life of the specimens was improved by the shot peening treatments, the improvement is shown 
in Fig. 2 which is the S-N curves of the shot peened specimens compared with the untreated material. It is clear that shot peening improved the fatigue life of the specimens. Higher shot peening intensity introduce higher compressive residual stress. The shoot peened specimens used for S-N curve was peened to the intensity of 0.0054 which introduce the lowest residual stress to shows that the other intensities has the same effects on the fatigue life since the residual stress introduce is higher than the residual stress introduce by the intensity of $0.0054 \mathrm{~A}$. The initial residual stress for the three shot peening intensities was measured using XRD. Shot peening intensity of $0.009,0.0067$ and $0.0054 \mathrm{~A}$ introduce $196 \pm 13.5,-179 \pm 12.5$ and $-168 \pm 12.8$ MPa of residual stress in the specimens respectively.

Figure $3 \mathrm{a}$ shows the relaxation of the residual stress for the load of $15.5 \mathrm{KN}$ for the three shot peening intensity. At the 10 cycle the measuring of the residual stress showed that the residual stress relaxed with $40 \pm 7$, $39 \pm 6$ and $38 \% \pm 6$ of the initial residual tress for the shot peening intensity of $0.0054,0.0067$ and $0.009 \mathrm{~A}$ respectively. At the 1000 cycles the initial residual stress relaxed by $43 \% \pm 7$ for $0.0054 \mathrm{~A}$ shot peening intensity, $42 \% \pm 6$ for $0.0067 \mathrm{~A}$ shot peening intensity and $42 \% \pm 6$ for $0.009 \mathrm{~A}$ shot peening intensity. At 10000 cycles the relaxation of the initial residual stress was $46 \% \pm 9$ for the shot peening intensity of $0.009 \mathrm{~A}$ while it is $45 \% \pm 8$ for the other intensities $(0.0054$ and $0.0067 \mathrm{~A})$ at the same cyclic number.

Figure $4 \mathrm{a}$ shows the relaxation of the residual stress for the load $30 \mathrm{KN}$. For the three intensities the maximum relaxation was observed at shot peening intensity of $0.0054 \mathrm{~A}$ which is $49 \pm 7,52 \pm 8$ and $54 \% \pm 7$ for the cyclic loads 10,1000 and 10000 respectively. Approximately the relaxation of the initial residual stress for the shot peening intensities of $0.0067 \mathrm{~A}$ and 0.009 are same percentage which is $47 \pm 8,48 \pm 7$ and $53 \% \pm 7$ for the cyclic loads of 10,1000 and 10000 respectively.

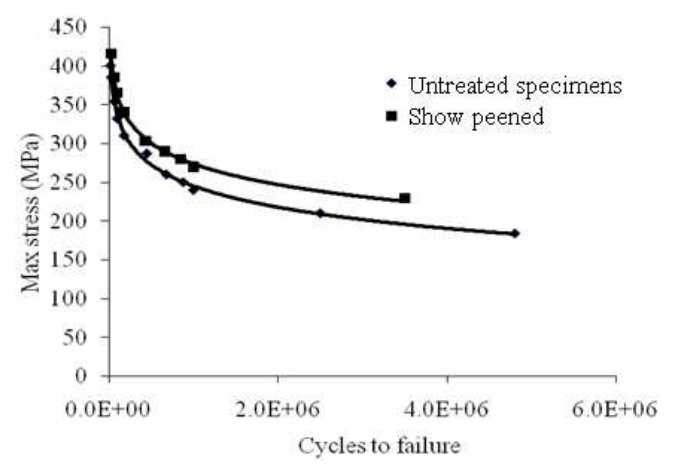

Fig. 2: S-N curves for peened and unpeened specimens
One specimen from each shot peening intensities were cyclic up to failure, residual stress measurements were performed on tested specimens after failure in a region far enough from the fracture surface (about 3 $\mathrm{mm}$ ) so that the material rupture was supposed not to have altered the residual stress field. The result showed that the relaxation have slightly variation with respect to the value measured at 10000 cycles.

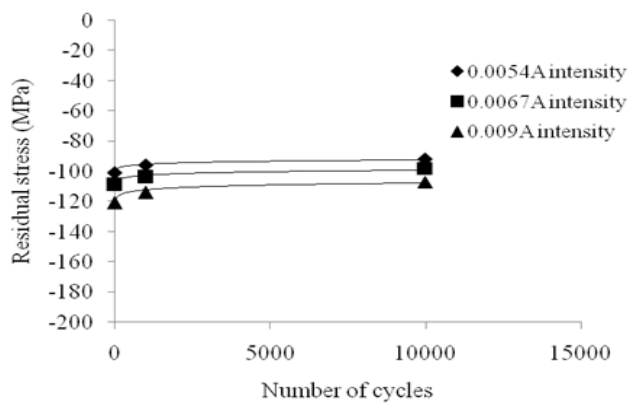

Fig. 3a: Residual stress relaxation of stress $15.5 \mathrm{KN}$

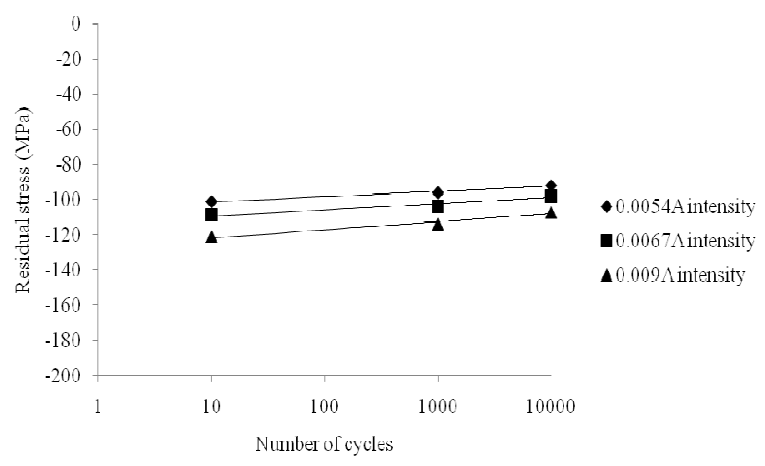

Fig. 3b: Logarithmic scale of residual stress relaxation of stress $15.5 \mathrm{KN}$

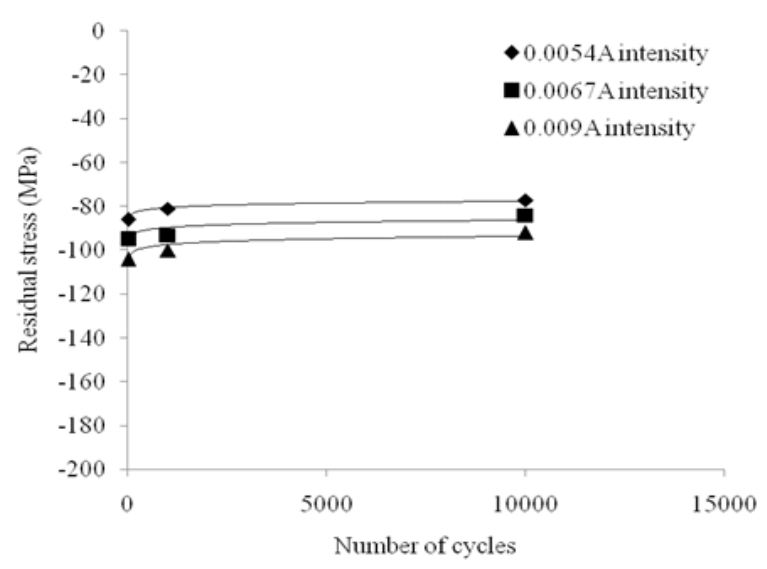

Fig. 4a: Residual stress relaxation of stress $30 \mathrm{KN}$ 


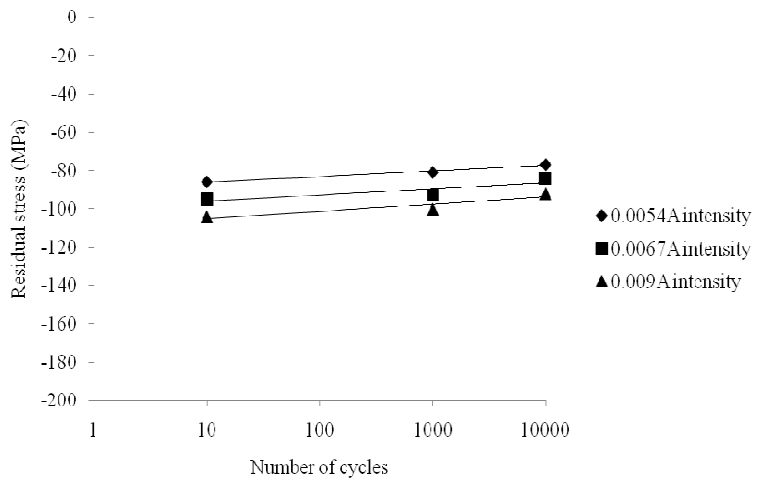

Fig. 4b: Logarithmic scale of residual stress relaxation of stress $30 \mathrm{KN}$

\section{DISCUSSION}

It is important to note that this study does not study the residual stress relaxation for number of cycles less than 10 as shown in Fig. $3 b$ and $4 b$ which represent Fig. 3a and $4 \mathrm{a}$ in the logarithmic scale respectively to show that the first few cyclic was not included.

Within the second phase relaxation, micro-plastic strains accumulating from cycle to cycle. Using Fig. 3b and $4 \mathrm{~b}$ the residual stress relaxation can be described as follows:

$$
\sigma_{\mathrm{rs}}=\sigma_{\mathrm{rs}}(\mathrm{N}-1)-\mu \cdot \log \mathrm{N}
$$

Where:

$$
\begin{aligned}
\sigma_{\mathrm{rs}}(\mathrm{N}-1)= & \text { Residual stress value after the first cycle } \\
\mu & =\begin{array}{l}
\text { A slope linearly depending on the stress } \\
\text { amplitude }
\end{array}
\end{aligned}
$$

This can depict the increase of residual stress relaxation with increasing number of cycles and loading stress amplitude. Critical loading stresses separating loading situations with cyclically stable and cyclically relaxing residual stresses can be determined by evaluation of the highest loading stress amplitude leading to $\mu=0$ or by measuring the dependence of the residual stresses remaining after the first and, e.g., the $10^{4 \text { th }}$ cycle on the loading stress amplitude and evaluation the lowest stress amplitude leading to changes of the residual stresses within this numbers of cycles $^{[5,8]}$.

The first and second phases of residual stress relaxation can easily be divided. Firstly, changes of the residual stresses occur within the first loading cycle. These are increasing with increasing loading stress amplitude and due to quasi-static relaxation effects.
Secondly, linear relationships between the residual stresses and the logarithm of the number of cycles come up which show increasing slopes with increasing loading stress amplitude.

\section{CONCLUSION}

The stability of residual stresses in 2024-T351 aluminum alloy, induced by different shot peening intensities due to cyclic loading was presented in this study. The focused of this study was only given on the relaxation of residual stress after the first cycle. The residual stress found to relax depends on the load amplitude. Load of $30 \mathrm{kN}$ made the specimens to relax more than the $15.5 \mathrm{kN}$ load. The maximum relaxation found is $54 \% \pm 7$ of the initial residual stress in the shot peen intensity of $0.0054 \mathrm{~A}$ after 10000 cycles for the load of $30 \mathrm{kN}$. The changed in the relaxation percentages of all specimens from 10 cyclic load to 10000 cyclic load is in the range of 5-8\% of the initial residual stress. This relaxation percentage is very low comparing it with the residual stress relaxation in the first stage which is more than $46 \%$ for the load $30 \mathrm{kN}$.

\section{ACKNOWLEDGEMENT}

The researchers would like to thanks Ministry of Higher Education, Malaysia for the Fundamental Research Grant that supporting this research.

\section{REFERENCES}

1. De Los Rios, E.R., A. Walley, M.T. Milan and G. Hammersley, 1995. Fatigue Crack initiation and propagation on shot-peened surfaces in A316 stainless steel. Int. J. Fatigue, 17: 493-499. http://cat.inist.fr/?aModele=afficheN\&cpsidt=2956680

2. Diepart, C.P., 1994. Modeling of shot peening residual stresses. practical applications. Mater. Sci. Forum, 163-165: 457-464. http://direct.bl.uk/bld/PlaceOrder.do?UIN=019380 208\&ETOC $=$ EN\&from $=$ searchengine

3. Ozdemir, A.T. and L. Edwards, 1997. Relaxation of residual stresses at cold worked fastener holes due to fatigue loading. Fatigue Fract. Eng. Mater. Struct., 20 : 1443-1451. http://cat.inist.fr/?aModele $=$ afficheN\&cpsidt $=2858728$

4. Holzapfel, H., V. Schulze, O. Vöhringer and E. Macherauch, 1998. Residual stress relaxation in an AISI 4140 steel due to quasistatic and cyclic loading at higher temperatures. Mater. Sci. Eng. A, 248: 9-18.

http://cat.inist.fr/?aModele=afficheN\&cpsidt=2268561 
5. Vohringer, O., 1987, Relaxation of Residual Stresses by Annealing or Mechanical Treatment. In: Advances in Surface Treatments Technology, Applications, Effects: Residual Stresses, Niku-Lari, A. (Eds.). Pergamon Press, ISBN: 9780080340623, pp 367-396.

6. Mattson, R.L. and W.S. Coleman Jr., 1954. Effect of shot peening variables and residual stresses on fatigue life of leaf spring specimens. Trans. Soc. Automot. $\quad$ Eng., 62: 546-556. https://shop.sae.org/technical/papers/540262

7. Champoux, R.L., J.H. Underwood and J.A. Kapp, 1988. Analytical and Experimental Methods for Residual Stress Effects in Fatigue. American Society for Test and Materials, USA., ISBN: 10: 0803111959, pp: 134.

8. Zhuang, W.Z. and G.R. Halford, 2001. Investigation of residual stress relaxation under cyclic load. Int. J. Fatigu., 23: S31-S37. http://cat.inist.fr/?aModele $=$ afficheN\&cpsidt=1339 0462
9. James, M.R., 1982. The relaxation of residual stresses during fatigue. Residual stress and stress relaxation. Sagamore Army Materials Research Conference Proceedings: Residual Stress and Stress Relaxation, E. Kula and V. Weiss, eds., Plenum Press, ISBN: 9780306411021, pp: 297-314.

10. Kodama, S., 1972. The behavior of residual stress during fatigue stress cycles. Proceeding of the International Conference on Mechanical Behavior of Metals, (ICMBM'72), Society of Material Science press, Kyoto, pp: 111-118.

11. Zaroog, O.S., A. Ali, B.B. Sahari and R. Zahari, 2009. Relaxation of residual stress. Part 1: Relaxation of stage 1. J. Sci. Ind. Res. (In press).

12. Airbus Industrie Test Method, (AITM) standards, (AITM 1-0011), 2001. Constant amplitude fatigue testing of metallic materials, AIRBUS INDUSTRIE, Editor. Airbus Industrie, Engineering Directorate, Blagnac cedex, France, pp: 1-24. 